\section{Seed moisture content, storage, viability and vigour}

Vertucci and Roos (1990) have proposed that moisture contents in equilibrium with $19-27 \%$ relative humidity $(\mathrm{RH})$ are optimal for the longevity of orthodox seeds in storage whereas we have suggested that those in equilibrium with about $10-11 \% \mathrm{RH}$ maximize the benefit to longevity from seed desiccation (Ellis et al., 1989, 1990a,b; Roberts and Ellis, 1989). These different recommendations are discussed here, not only for scientific interest, but because immediate decisions on conditions for long-term seed storage for genetic conservation cannot be avoided since they are already implicit in current practice.

Drying increases the longevity of orthodox seeds in a predictable way (Roberts, 1973), and it has long been known that they can survive considerable desiccation; for example, neither the viability nor the vigour of seeds of five gramineous species was adversely affected by drying to $1 \%$ moisture content
(Harrington and Crocker, 1918). Moreover, desiccation to very low moisture contents, typically to $1-2 \%$, can be advantageous to longevity (Evans, 1957; Nutile, 1964). Because of the long periods required for loss of viability in dry seeds, however, knowledge of the moisture content(s) at which orthodox seed longevity is maximal has been lacking.

The effect of seed moisture content on longevity can be quantified by a negative logarithmic relation (Ellis and Roberts, 1980a). This relation continued down to $2.1 \%$ moisture content in sesame (Sesamum indicum L.) stored at $50^{\circ} \mathrm{C}$, but 4 years of experimental storage was required to obtain a seed survival curve in this environment (Ellis et al., 1986). And so in more recent work we have stored seeds at $65^{\circ} \mathrm{C}$ to obtain complete seed survival curves at low moisture contents within 6-12 months. By so doing we detected a low-moisture-content limit $\left(m_{\mathrm{c}}\right)$ to the negative logarithmic relation between seed longevity and moisture in air-dry storage and more often than not we found that desiccation below $m_{\mathrm{c}}$ (by 1-3\%) had no further effect on longevity (Ellis et al., 1988, 1989, 1990a,b). These investigations in diverse species exposed considerable variation in the value of $m_{c}$ which appears to result from differences in seed

Table 1. Comparison of reported critical moisture contents $\left(m_{\mathrm{c}}\right)$ and relative humidities (RH) at which longevity, seed vigour and thermal-chemical reactions are optimal

\begin{tabular}{|c|c|c|c|c|c|c|}
\hline \multirow{3}{*}{$\begin{array}{l}\text { Species } \\
\text { (common name) }\end{array}$} & \multicolumn{6}{|c|}{ Optimal values } \\
\hline & \multicolumn{2}{|c|}{ Longevity at $65^{\circ} \mathrm{C}$} & \multicolumn{2}{|c|}{ Vigour at $35^{\circ} \mathrm{C}$} & \multicolumn{2}{|c|}{$\begin{array}{l}\text { Thermal-chemical } \\
\text { reactions }\end{array}$} \\
\hline & $\begin{array}{c}m_{\mathrm{c}} \\
(\%, \mathrm{f} . \mathrm{wt})\end{array}$ & $\begin{array}{l}\mathrm{RH} \\
(\%)\end{array}$ & $\begin{array}{c}m_{\mathrm{c}} \\
(\%, \mathrm{f} . \mathrm{wt})\end{array}$ & $\begin{array}{l}\mathrm{RH} \\
(\%)\end{array}$ & $\begin{array}{c}m_{\mathrm{c}} \\
(\%, \mathrm{f} . \mathrm{wt})\end{array}$ & $\begin{array}{l}\mathrm{RH} \\
(\%)\end{array}$ \\
\hline $\begin{array}{l}\text { Arachis hypogaea } \mathrm{L} \text {. } \\
\text { (groundnut) }\end{array}$ & $2.0^{\mathrm{a}}$ & $11^{\mathrm{a}}$ & $3.3^{\mathrm{b}}$ & $16^{\mathrm{b}}$ & $4.1^{\mathrm{b}}$ & $25^{\mathrm{b}}$ \\
\hline $\begin{array}{l}\text { Glycine max (L.) Merr. } \\
\text { (soyabean) }\end{array}$ & $\leqslant 3.3^{\mathrm{a}}$ & $\leqslant 11^{\mathrm{a}}$ & $5.6^{\mathrm{b}}$ & $20^{\mathrm{b}}$ & $6.3^{b}$ & $28^{\mathrm{b}}$ \\
\hline $\begin{array}{l}\text { Helianthus annuus L. } \\
\text { (sunflower) }\end{array}$ & $2.0^{\mathrm{c}}$ & n.d. ${ }^{d}$ & $3.0^{\mathrm{b}}$ & $18^{\mathrm{b}}$ & $3.3^{\mathrm{b}}$ & $28^{\mathrm{b}}$ \\
\hline $\begin{array}{l}\text { Lactuca sativa L. } \\
\text { (lettuce) }\end{array}$ & $2.6^{\mathrm{e}}$ & $10^{\mathrm{e}}$ & $4.5^{\mathrm{b}}$ & $21^{\mathrm{b}}$ & $5.2^{\mathrm{b}}$ & $29^{\mathrm{b}}$ \\
\hline $\begin{array}{l}\text { Pisum sativum } \mathrm{L} . \\
\text { (pea) }\end{array}$ & $6.2^{\mathrm{e}}$ & $11^{\mathrm{e}}$ & $6.6^{b}$ & $19^{b}$ & $7.8^{\mathrm{b}}$ & $28^{b}$ \\
\hline
\end{tabular}

${ }^{\mathrm{a}}$ From Ellis et al. (1990b).

'From Vertucci and Roos (1990), but seed moisture contents have been converted here to f. wt basis.

'From Ellis et al. (1988).

dn.d., not determined, but likely to be $10-11 \%$ from standard isotherms for this crop.

'From Ellis et al. (1989). 
composition. This is because the equilibrium relative humidity of the seeds at $m_{\mathrm{c}}$ is similar at about 10-11\% (Ellis et al., 1989, 1990a,b; Roberts and Ellis, 1989). As a result we have suggested that drying seeds to moisture contents in equilibrium with $10-11 \% \mathrm{RH}$ will maximize the benefits to longevity from desiccation and that such advice could be employed in seed genebanks.

Vertucci and Roos (1990) have recently reported two different approaches based on predicted effects of moisture on thermal-chemical reaction rates, and measurements of seed vigour after storage for 2 or 4 months at $35^{\circ} \mathrm{C}$. The vigour test results (percentage germination $\times$ mean root length) were related curvilinearly with moisture whereby the greatest values were obtained at intermediate moisture contents. A comparison of the 'optimal' moisture contents and equilibrium relative humidities for the five species common to both studies shows wide disparities among the three criteria (Table 1). Although they did not determine longevity, Vertucci and Roos (1990) proposed that moisture contents in equilibrium with $19-27 \%$ RH are optimal for seed longevity, i.e. substantially greater than our proposal.

Vertucci and Roos (1990) suggest that their recommendation is more appropriate because our germination tests were not sensitive enough to measure decline in vigour and because our temperature was much higher than that used in seed storage practice. We do not accept the first criticism because we in fact reported longevity estimated from entire survival curves and not from a single germination test result, and it is well known that the determination of seed longevity provides one approach to determining seed vigour (Matthews, 1980) and, when entire survival curves are examined, it can be a sensitive method. Moreover, longevity is surely the relevant criterion for study to provide advice to maximize longevity. An experimental temperature of $65^{\circ} \mathrm{C}$ is clearly very much warmer than those advocated (typically $-20^{\circ} \mathrm{C}$ ) for long-term seed storage (but so is $35^{\circ} \mathrm{C}$ ). However, results obtained at $65^{\circ} \mathrm{C}$ cannot simply be dismissed when it is now well established that: (a) there is a continuous relation between seed longevity and temperature between at least $-13^{\circ} \mathrm{C}$ and $+80^{\circ} \mathrm{C}$ (Dickie et al., 1990); and (b) there is no interaction between the effects of temperature and moisture on seed longevity when these relations are quantified by the seed viability equation (e.g. Ellis and Roberts, 1980a,b; Ellis et al., 1982; Kraak and Vos, 1987), i.e. there is no evidence that the relative effect of moisture content on longevity varies with temperature.

We have found no evidence that seed vigour is maintained better in storage at moisture contents in equilibrium with $19-27 \%$ than with $10-11 \% \mathrm{RH}$ in our studies at temperatures cooler than $65^{\circ} \mathrm{C}$. Figure 1 shows germination progress curves for seeds of three pasture legumes after 18 months of storage at $40^{\circ} \mathrm{C}$.

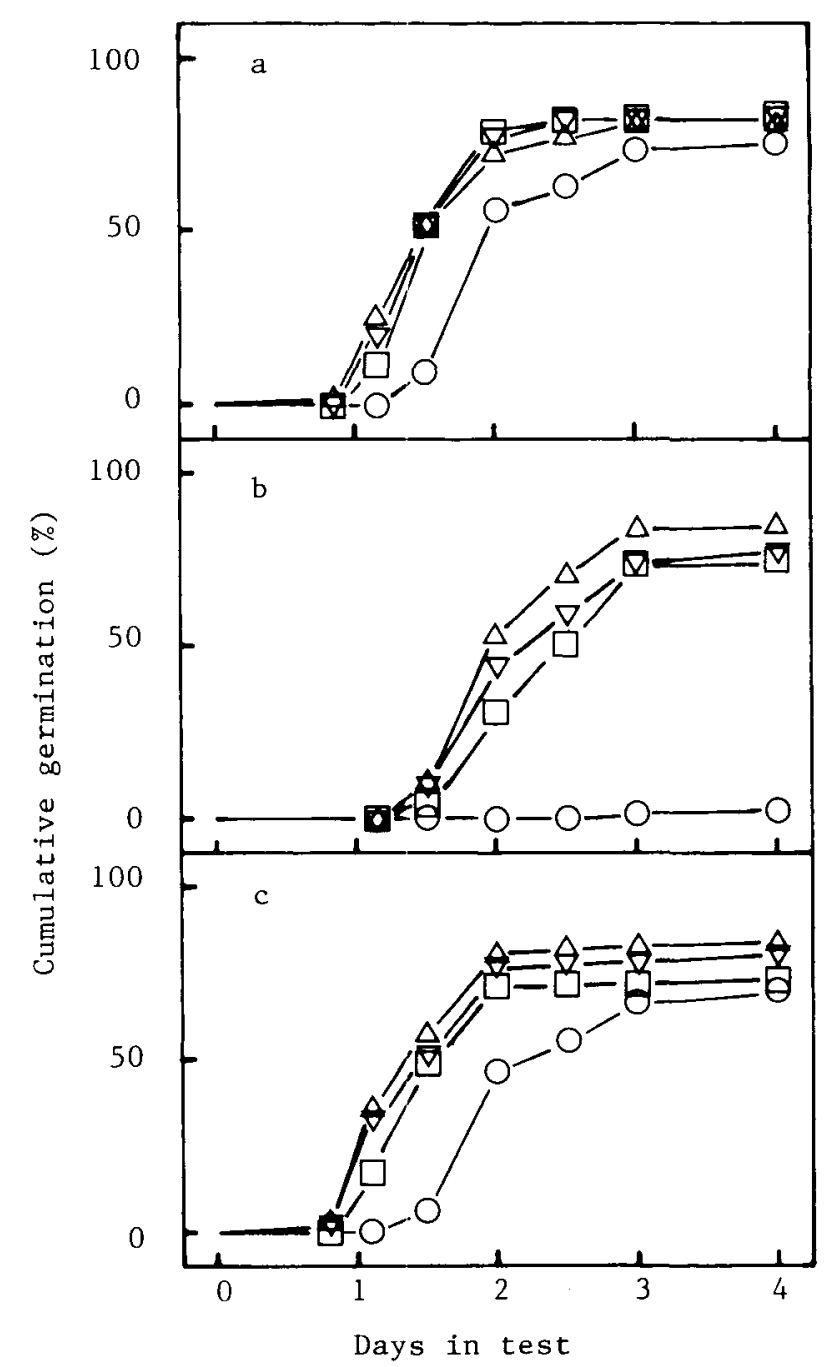

Figure 1. Progress of germination of seeds of lucerne ( $M e d-$ icago sativa L.) (a), red clover (Trifolium pratense L.) (b), and white clover (Trifolium repens $\mathbf{L}$.) (c) following dry or ultra-dry storage for $553 \mathrm{~d}$ at $40^{\circ} \mathrm{C}$. Seed storage moisture contents (f. wt) and equilibrium relative humidities were: $4.2 \% \mathrm{MC}$ and $10.8 \% \mathrm{RH}(\triangle), 4.8 \% \mathrm{MC}$ and $14.0 \% \mathrm{RH}$ $(\nabla), 6.1 \% \mathrm{MC}$ and $19.1 \% \mathrm{RH}(\square)$, and $7.0 \% \mathrm{MC}$ and $28.9 \% \mathrm{RH}(\bigcirc)$ in a; $3.7 \% \mathrm{MC}$ and $10.8 \% \mathrm{RH}(\triangle), 4.7 \%$ $\mathrm{MC}$ and $11.6 \% \mathrm{RH}(\nabla), 6.1 \% \mathrm{MC}$ and $16.2 \% \mathrm{RH}(\square)$, and $7.6 \% \mathrm{MC}$ and $28.1 \% \mathrm{RH}(\mathrm{O})$ in $\mathrm{b} ; 3.8 \% \mathrm{MC}$ and $11.2 \% \mathrm{RH}(\triangle), 4.1 \% \mathrm{MC}$ and $12.0 \% \mathrm{RH}(\nabla), 6.1 \% \mathrm{MC}$ and $18.1 \% \mathrm{RH}(\square)$, and $7.7 \% \mathrm{MC}$ and $29.7 \% \mathrm{RH}(\mathrm{O})$ in c. Seeds were tested for germination at $20^{\circ} \mathrm{C}$ after humidification over water at $20^{\circ} \mathrm{C}$ for $1 \mathrm{~d}$ to $14-15 \%$ moisture content (to avoid imbibition damage).

In all three species percentage germination and rate (i.e. rapidity) of germination were poorest for seeds stored at moisture contents in equilibrium with $28-30 \% \mathrm{RH}$. Differences following storage at lower moisture contents were less marked. In both clovers (Fig. 1b,c) they were entirely consistent with a pro- 
gressive decline in the rate of loss of viability and vigour with decline in equilibrium relative humidity from $19 \%$ to $11 \%$. In lucerne (Fig. la) the differences were less; early germination was greatest for seeds stored at $11 \%$ and $14 \% \mathrm{RH}$ but results after $4 \mathrm{~d}$ in test were almost identical for seeds at $11-19 \%$ RH. Thus, despite storing seeds at a temperature $5^{\circ} \mathrm{C}$ warmer and for a period 4.5-9 times longer than that employed by Vertucci and Roos, we found no evidence to support their observation that seed vigour is greater following storage in equilibrium with $19-27 \%$ than $10-11 \% \mathrm{RH}$. Indeed, the results are compatible with our proposal that $10-11 \% \mathrm{RH}$ is preferable to higher values for maximizing longevity.

We believe that our observations for both longevity and vigour in short- and medium-term studies of dry and ultra-dry seed storage are consistent with the results of longer-term studies elsewhere. In particular, in an earlier long-term study at Vertucci and Roos's own laboratory, Bass and Stanwood (1978) reported results of 16 years of storage of sorghum (Sorghum bicolor (L.) Moench.) at temperatures between $-12^{\circ} \mathrm{C}$ and $32^{\circ} \mathrm{C}$ with $4.8-10.0 \%$ moisture content (f. wt); seed survival was better at $4.8 \%$ than at $7.0 \%$ and better at $7.0 \%$ than at $10.0 \%$. Now $4.8 \%$ moisture content in sorghum provides an equilibrium relative humidity close to the value of $10-11 \%$ which we propose for long-term seed storage, whereas $7.0 \%$ and $10.0 \%$ provide values close to the lower and upper limits of $19 \%$ and $27 \%$ RH proposed by Vertucci and Roos (Justice and Bass, 1978).

Thus, we believe that the proposal that moisture contents in equilibrium with $19-27 \%$ RH are optimal for seed longevity (Vertucci and Roos, 1990) is not well supported. (We thank the International Board for Plant Genetic Resources for financial support.)

\section{References}

Bass, L.N. and Stanwood, P.C. (1978) Long-term preservation of sorghum seed as affected by seed moisture, temperature, and atmospheric environment. Crop Science 18, 575-577.

Dickie, J.B., Ellis, R.H., Kraak, H.L., Ryder, K. and Tompsett, P.B. (1990) Temperature and seed storage longevity. Annals of Botany 65, 197-204.

Ellis, R.H. and Roberts, E.H. (1980a) Improved equations for the prediction of seed longevity. Annals of Botany 45, 13-30.
Ellis, R.H. and Roberts, E.H. (1980b) The influence of temperature and moisture on seed viability in barley (Hordeum distichum L.). Annals of Botany 45, 31-37.

Ellis, R.H., Osei-Bonsu, K. and Roberts, E.H. (1982) The influence of genotype, temperature and moisture on seed longevity in chickpea, cowpea and soyabean. Annals of Botany 50, 69-82.

Ellis, R.H., Hong, T.D. and Roberts, E.H. (1986) Logarithmic relationship between moisture content and longevity in sesame seeds. Annals of Botany 57, 499-503.

Ellis, R.H., Hong, T.D. and Roberts, E.H. (1988) A lowmoisture-content limit to logarithmic relations between seed moisture content and longevity. Annals of Botany 61, 405-408.

Ellis, R.H., Hong, T.D. and Roberts, E.H. (1989) A comparison of the low-moisture-content limit to the logarithmic relation between seed moisture and longevity in twelve species. Annals of Botany 63, 601-611.

Ellis, R.H., Hong, T.D. and Roberts, E.H. (1990a) Moisture content and the longevity of seeds of Phaseolus vulgaris. Annals of Botany 66, 341-348.

Ellis, R.H., Hong, T.D., Roberts, E.H. and Tao, K.-L. (1990b) Low-moisture-content limits to relations between seed longevity and moisture. Annals of Botany 65, 493-504

Evans, G. (1957) The viability over a period of fifteen years of severely dried ryegrass seed. Journal of the British Grassland Society 12, 286-289.

Harrington, G.T. and Crocker, W. (1918) Resistance of seeds to desiccation. Journal of Agricultural Research 14, $525-532$

Justice, O.L. and Bass, L.N. (1978) Principles and practices of seed storage. Washington DC, US Government Printing Office.

Kraak, H.L. and Vos, J. (1987) Seed viability constants for lettuce. Annals of Botany 59, 343-349.

Matthews, S. (1980) Controlled deterioration: a new vigour test for crop seeds. pp. 647-660 in Hebblethwaite, P.D. (Ed.) Seed production. London, Butterworth.

Nutile, G.E. (1964) Effect of desiccation on viability of seeds. Crop Science 4, 325-328.

Roberts, E.H. (1973) Predicting the storage life of seeds. Seed Science and Technology 1, 499-514

Roberts, E.H. and Ellis, R.H. (1989) Water and seed survival. Annals of Botany 63, 39-52.

Vertucci, C.W. and Roos, E.E. (1990) Theoretical basis of protocols for seed storage. Plant Physiology 94, 1019 1023.

R. H. Ellis*, T. D. Hong and E. H. Roberts Department of Agriculture, University of Ręading, Earley Gate, PO Box 236, Reading RG6 2AT, UK

\section{RESPONSE}

We are pleased that our paper (Vertucci and Roos, 1990) has generated such interest and welcome the opportunity to reply to some of the questions raised by Ellis and coauthors in their letter to the Editor.
Our work was criticized because our prediction of the optimum relative humidity for seed storage (between 19 and $27 \% \mathrm{RH}$ ) is greater than what has been suggested by Ellis et al. $(1989,1990)(10 \% \mathrm{RH})$, 
and because our experimental findings indicate that overdrying seeds can reduce their longevity. The paper in question introduces the concept of using physical principles to predict optimum storage conditions for orthodox seeds, as theoretical considerations can describe the metabolic potential of seeds at various moisture levels. Our approach has distinct advantages that the purely empirical approach used by Ellis and coworkers lacks: (1) it gives greater insights into the role that water plays in controlling seed deterioration rates and hence a better understanding of the mechanisms of seed ageing, and (2) it allows us to develop generic protocols for optimizing the moisture level for storage of seeds with varying chemical compositions. At present, the International Board for Plant Genetic Resources (IBPGR) recommends that seeds be stored at moisture contents between 3 and $7 \%$, but it is well-known that the optimum moisture content will vary among seed species, cultivars and lots.

It is important to point out that the conditions unequivocally optimal for seed storage are unknown - and are likely to remain unknown for at least 20 years. Thus, predictive models have been developed to estimate seed deterioration rates under given storage conditions. At the USDA National Seed Storage Laboratory, we are studying the types of reactions that occur at low moisture contents, and how moisture content controls the kinetics. From this information, we infer the moisture level at which deleterious reactions will be minimized. Ellis et al. $(1989,1990)$ measure the rate of deterioration under extreme conditions (high temperatures) and then extrapolate beyond their data to determine ageing rates under milder conditions. It is a credit to the two approaches that our separate laboratories have such similar findings. However, our results differ in two significant ways: the relative humidity of the critical moisture content and whether drying to moisture contents below the critical value is damaging.

Ellis and coworkers have determined that there is a critical moisture level to which seeds can be dried for maximum longevity, and that further drying has no additional benefits. We have also established that there is a critical moisture level for maximum longevity, but that further drying may accelerate the rate of seed deterioration. The critical moisture level given by Ellis and coworkers corresponds to a relative humidity of about $10 \%$, while that given by our laboratory lies in a range between 19 and $27 \% \mathrm{RH}$. The lower limit of this range is derived from experiments conducted at $35^{\circ} \mathrm{C}$, but with results interpreted on isotherms made at $25^{\circ} \mathrm{C}$. We expressed reservations about this approach in our paper, but the present controversy has prompted us to analyse the problem in more detail.

The relationship between equilibrium moisture content and relative humidity varies with temperature (Fig. 2; Vertucci and Leopold, 1987), such that at a

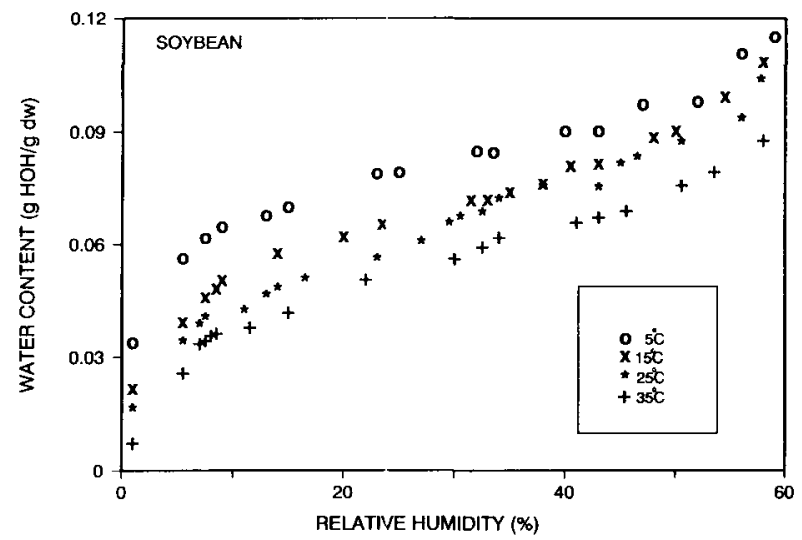

Figure 2. Water sorption isotherms of soybean seeds collected at $5,15,25$ and $35^{\circ} \mathrm{C}$. Methods are described in Vertucci and Leopold (1987). Notice that the relative humidity at a given water content is greater for higher temperatures.

given 'coverage' or water content the corresponding water activity will be greater at higher temperatures. This is the principle of Clausius-Clapeyron theory. Van't Hoff analysis states that, for a given water coverage, the natural logarithm of the water activity is linearly related to the reciprocal of absolute temperature. Consequently, we can apply van't Hoff analyses to pea, soybean and peanut data for which we have isotherms collected from at least three temperatures in the range of $5^{\circ}$ and $35^{\circ} \mathrm{C}$ (Vertucci and Leopold, 1987). In doing so, we have determined that the relative humidity corresponding to the optimum moisture content for storage at $35^{\circ} \mathrm{C}$ (Vertucci and Roos, 1990; and Table 1, Ellis et al., above) is actually about $25 \%$ for each species. This value differs from the $16-21 \% \mathrm{RH}$ that we suggested previously, and agrees remarkably well with the relative humidity at which thermal-chemical reactions are minimized by low diffusion coefficients (Vertucci and Roos, 1990; and Table 1, Ellis et al., above).

The value of $10 \% \mathrm{RH}$, given as the optimum relative humidity by Ellis and coworkers, was derived in a similar manner as ours except that ageing experiments were performed at $65^{\circ} \mathrm{C}$, but results were interpreted on isotherms made at $20^{\circ} \mathrm{C}$. Given that temperature will affect the water activity of seeds at a given water content, we have reanalysed optimum moisture content data given by Ellis and coworkers (Table 1 above) using van't Hoff analyses (Fig. 3). The water activities (assumed to be RH/100) corresponding to the optimum water contents of $2,3.3$ and $6.2 \%$ given by Ellis and coworkers for peanut, soybean and pea, respectively, were determined for temperatures between $5^{\circ}$ and $35^{\circ} \mathrm{C}$ from isotherms made at given temperatures. This treatment is flawed, since our isotherms may not be appropriate to interpret data collected by Ellis and coworkers because the moisture content determinations and the cultivars 
used differ between the two laboratories. (In particular, water content determinations vary by method and cannot be calibrated. This is another incentive for using relative humidity rather than moisture content as the parameter by which optimum moisture level is measured.) Foregoing this concern, if we extrapolate the line, predicted by van't Hoff analysis of water content data collected between $5^{\circ}$ and $35^{\circ} \mathrm{C}$ (Fig. 3), we find that peanut, soybean and pea seeds with $2.0,3.3$ and $6.2 \%$ water are in equilibrium with a 28,31 and $46 \% \mathrm{RH}$ at $65^{\circ} \mathrm{C}$. This means that $\mathrm{RH}$ for maximum longevity at $65^{\circ} \mathrm{C}$ may actually be considerably greater than the $10 \% \mathrm{RH}$ given by Ellis and coworkers.

Another point of controversy is the question of whether drying to moisture levels less than the optimum relative humidity actually reduces seed longevity. There may be many explanations for the conflicting data that have been gathered by several laboratories (some of these are discussed in Vertucci and Roos (1990)). In this letter, we would like to suggest a simple explanation that is based on the interaction between water content, relative humidity, and temperature. In our paper (Vertucci and Roos, 1990) and in this letter, we have suggested that a relative humidity of about $25 \%$ is optimal for seed storage. Through extrapolations of van't Hoff analyses of isotherms collected at $5^{\circ}$ to $35^{\circ} \mathrm{C}$, we can predict that equilibrium moisture contents corresponding to $25 \% \mathrm{RH}$ and $65^{\circ} \mathrm{C}$ are $1.7,2.3$ and $3.2 \%$ (Fig. not shown) water for peanut, soybean and pea respectively. We suggest that these water contents represent the moisture levels for maximum longevity of seeds at $65^{\circ} \mathrm{C}$. In the experiments published by Ellis and coworkers, the lowest moisture contents studied were about $1.5,3.3$ and $3.6 \%$ for peanut, soybean and pea, respectively (Ellis et al., 1990; Ellis et al., 1989). Perhaps, the reason why deleterious effects of overdrying have not been reported in some laboratories is that low enough moisture contents have not been studied. We maintain, that when studying the interaction between seed deterioration rates and moisture level, the water activity of the seed must be considered. The water activity of seeds with a given water content will vary with the temperature as well as the chemical composition of the seed.

Naturally, experiments to test our predictions are needed. In the meantime, decisions must be made on how we should store valuable germplasm. We (and other laboratories) have shown that seeds that are dried below a critical moisture level lose vigour at a faster rate than those stored at an optimum level. There are numerous studies demonstrating detrimental effects of extremely low moisture contents on the structure and function of proteins, membrane lipids and nucleic acids (discussed in Vertucci and Roos, 1990). Ellis and coworkers have shown that while they detect no deleterious effects, there are no advan-

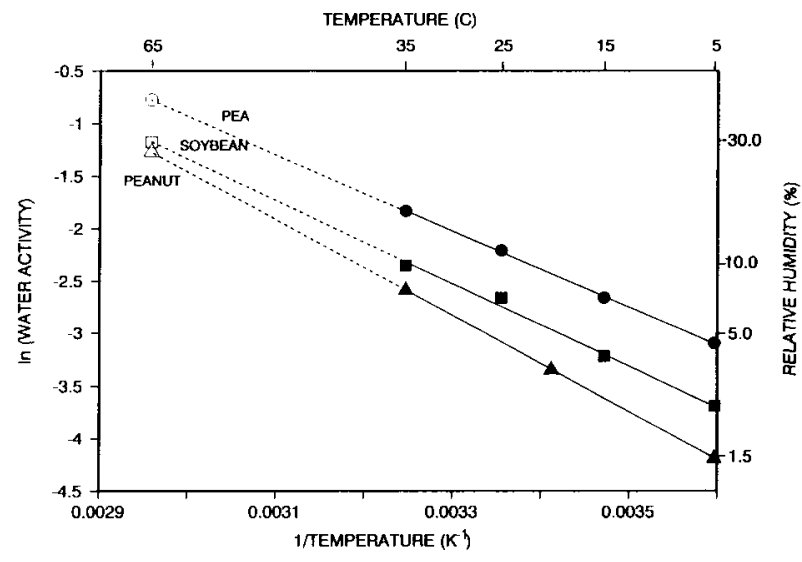

Figure 3. Van't Hoff analyses of peanut, soybean and pea seeds at 2.0,3.3 and $6.2 \%$ water, respectively. Water activity values for each temperature are derived from isotherms as in Fig. 2 (isotherms for pea and peanut are not shown, but are similar to isotherms for soybean). Solid lines represent the least-squares regression of the $\ln (\mathrm{RH} / 100)$ and $1 / \mathrm{T}$ relationship. Dashed line represents the extrapolation of the least-squares regression to $65^{\circ} \mathrm{C}$. Notice that the relative humidity corresponding to the critical moisture contents at $65^{\circ} \mathrm{C}$ is actually between 28 and $46 \%$.

tages to overdrying either. Rather than ignore our findings, we believe a more conservative approach, where seeds are not dried below a critical moisture level, will preclude the possibility of inadvertently accelerating the deterioration process by overdrying. The critical moisture level remains unknown. We believe that our colleagues must consider the effect of temperature on the water activity of seeds at a given water content before they draw firm conclusions.

\section{References}

Ellis, R.H., Hong, T.D., Roberts, E.H. (1989) A comparison of the low-moisture-content limit to the logarithmic relation between seed moisture and longevity in twelve species. Annals of Botany 63, 601-611.

Ellis, R.H., Hong, T.D., Roberts, E.H. and Tao, K.-L. (1990) Low-moisture-content limits to relations between seed longevity and moisture. Annals of Botany 65, 493-504.

Vertucci, C.W. and Leopold, A.C. (1987) Water binding in legume seeds. Plant Physiology 85, 224-231.

Vertucci, C.W. and Roos, E.E. (1990) Theoretical basis of protocols for seed storage. Plant Physiology 94, 1019 1023.

Christina W. Vertucci* and Eric E. Roos United States Department of Agriculture Agricultural Research Service, National Seed Storage Laboratory, Fort Collins, CO 80523, USA

(C) C.A.B International, 1991 